\title{
Caso Clínico Radiológico Pediátrico
}

\author{
NATALIA RETAMALES M.* y CRISTIÁN GARCÍA B.**
}

\section{Historia clínica}

Paciente de sexo masculino de 3 meses de edad con historia de tos, fiebre y decaimiento, de tres días de evolución, por lo que consulta en el Servicio de Urgencia. Al examen físico, está febril $\left(38{ }^{\circ} \mathrm{C}\right.$ axilar), con coriza y secreción nasal mucosa, relativamente en buen estado ge- neral. El examen pulmonar muestra disminución del murmullo pulmonar en la base pulmonar derecha.

Dentro de su estudio se solicita radiografía $(\mathrm{Rx})$ de tórax en proyecciones anteroposterior (AP) y lateral (Figura 1) para descartar una neumonía.

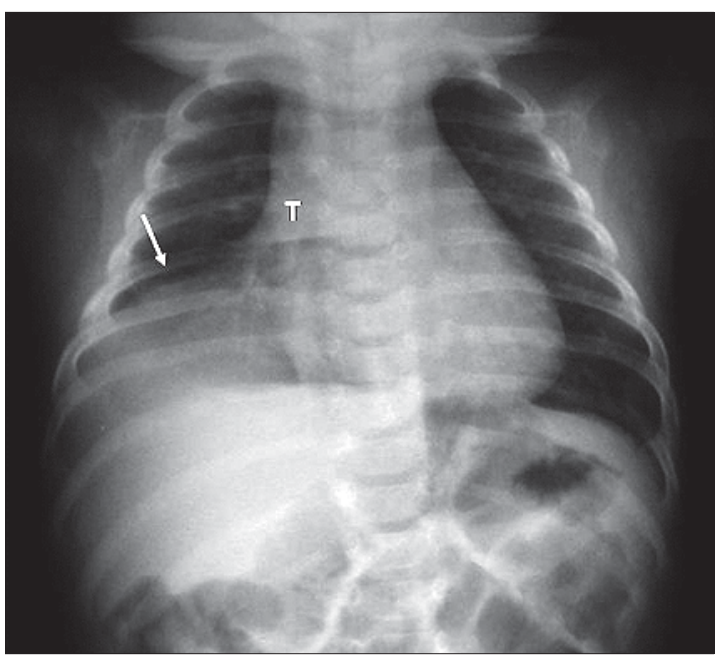

Figura 1a. Radiografía de tórax en proyección anteroposterior.

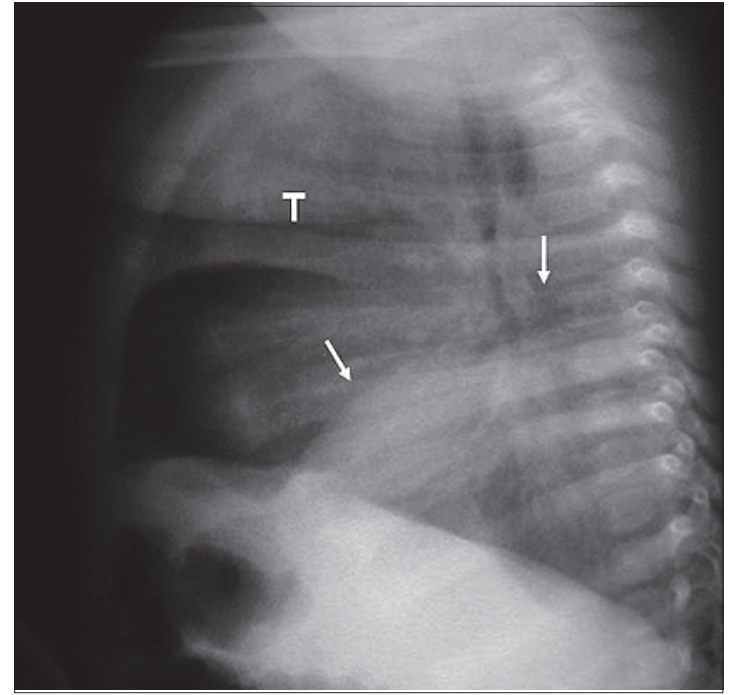

Figura 1b. Radiografía de tórax en proyección lateral.

¿Cuál es su hipótesis diagnóstica?

\footnotetext{
* $\quad$ Residente $3^{\text {er }}$ año Pediatría, Facultad de Medicina, Pontificia Universidad Católica de Chile.

** Profesor titular, Departamentos de Radiología y Pediatría, Facultad de Medicina, Pontificia Universidad Católica de Chile.
} 


\section{Hallazgos radiológicos}

La Figura 1 muestra una opacidad de la base del hemitórax derecho, que en la proyección lateral se manifiesta como una lobulación posterior (flechas). Junto con esto, en el hipocondrio derecho se identifica la sombra del hígado $(\mathrm{H})$ relativamente pequeña, lo que sugiere que la opacidad de la base derecha del tórax, probablemente corresponde al hígado parcialmente ascendido. Considerando esto, el diagnóstico diferencial debe incluir una parálisis, eventración o hernia diafragmática, con ascenso secundario del hígado. Ahora bien, en la proyección lateral se ve que el ascenso compromete sólo los dos tercios posteriores del hemidiafragma derecho, lo que prácticamente descarta una parálisis diafragmática. Por lo tanto, el primer diagnóstico debería ser el de una eventración diafragmática parcial. Si bien no es posible descartar una hernia diafragmática, esta es menos probable.

El examen indicado a continuación fue una ultrasonografía (US) abdominal, la que puede confirmar que la opacidad descrita en la base del tórax corresponde efectivamente al hígado (normal). Además, permite evaluar la movilidad diafragmática.

En este paciente, la US confirmó el ascenso del hígado, el que era por lo demás normal. Mostró además una marcada disminución en la movilidad del hemidiafragma derecho, sin movimiento paradojal (Figura 2). Todos estos hallazgos son compatibles con una eventración diafragmática. Si bien la US no permite descartar con certeza un defecto diafragmático, esto es mucho menos probable por frecuencia, por la edad de presentación y por el compromiso parcial del diafragma.

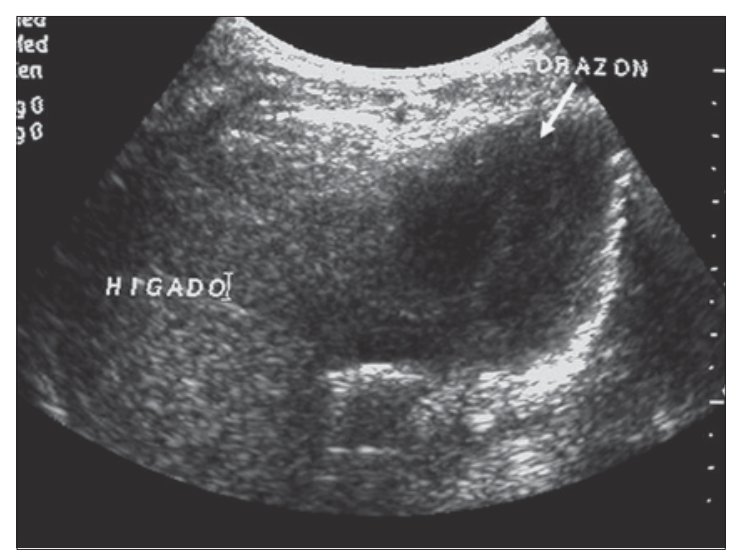

Figura 2. Ultrasonografía abdominal (ver descripción en el texto).
El paciente fue sometido a cirugía en forma electiva, donde se confirmó el diagnóstico de una eventración diafragmática derecha, la que fue corregida con una plicatura. El niño evolucionó clínicamente bien, asintomático y en una Rx de tórax efectuada un mes más tarde, el diafragma estaba en posición normal.

\section{Diagnóstico}

Eventración diafragmática derecha.

\section{Discusión}

La eventración diafragmática se define como la elevación anormal, parcial o total del diafragma, sin un defecto de continuidad, asociado a un defecto en el músculo diafragmático ${ }^{1-6}$. Puede clasificarse según su etiología en congénita o adquirida y ambas formas pueden confundirse con hernia diafragmática.

Es una patología poco frecuente en pediatría. Existen algunos reportes que muestran una incidencia de 1-3/1.000 recién nacidos vivos ${ }^{1}$.

La eventración diafragmática congénita se produce por un defecto en el desarrollo del diafragma durante el primer trimestre del embarazo, debido a la falla en la migración de mioblastos hacia la membrana pleuroperitoneal, que formará parte del diafragma o a una falla en la inervación de éstos ${ }^{2}$. Usualmente es unilateral, más comúnmente al lado izquierdo y puede comprometer parcial o totalmente el diafragma ${ }^{3}$. Puede presentarse como una anomalía aislada o como parte de un Síndrome, entre ellos los Síndromes de Kabuki, Beckwith-Wiedeman y Poland. Se han descrito casos en relación a infecciones durante el primer trimestre del embarazo como rubéola y citomegalovirus ${ }^{4}$.

La eventración adquirida del diafragma resulta de una parálisis del nervio frénico, con atrofia muscular secundaria, generalmente asociada a trauma obstétrico en el recién nacido, cirugía cardíaca o traumatismo externo ${ }^{5}$.

En ambas formas, la musculatura diafragmática está adelgazada y en su reemplazo existe tejido fibroso laxo, lo que limita su movilidad y permite su ascenso, produciendo como consecuencia limitación en la expansión pulmonar.

Las manifestaciones clínicas son variadas y dependen esencialmente de la magnitud de la lesión, variando desde una presentación asintomática hasta un severo distrés respiratorio.

La signología respiratoria se produce por dis- 
minución de la capacidad de expansión pulmonar en el lado afectado y en ocasiones en el pulmón contralateral por desviación del mediastino cuando el defecto es mayor. También puede presentarse clínicamente como obstrucción bronquial y neumonías repetidas, atelectasias o bronquiec$\operatorname{tasias}^{3,5,7}$.

El paciente puede presentar además síntomas gastrointestinales como regurgitación, vómitos y dificultad en la alimentación, por una angulación anormal entre el esófago distal y el estómago cuando el defecto está al lado izquier$\mathrm{do}^{3,5,6}$.

El diagnóstico se sospecha con la Rx de tórax, que muestra como hallazgo, elevación de un hemidiafragma y la consiguiente disminución de volumen pulmonar ipsilateral en un paciente asintomático o con signología respiratoria ${ }^{3,5}$. La US muestra elevación y disminución de la movilidad del diafragma en la zona afectada y además permite evaluar las estructuras intraabdominales e infradiafragmáticas. Otro método diagnóstico lo constituye la fluoroscopía que permite demostrar la disminución o ausencia de la movilidad diafragmática o su movimiento paradojal. En algunos casos la electromiografía es útil para confirmar la parálisis del nervio frénico en la eventración diafragmática adquirida.

Con respecto al tratamiento, numerosas publicaciones justifican la reparación quirúrgica del defecto en aquellos casos sintomáticos o con un defecto muy amplio ${ }^{3,8-12}$, mediante la plicatura del diafragma comprometido, disminuyendo su superficie y aumentando la tensión de éste sobre los órganos intraabdominales, con el fin de permitir una buena expansión pulmonar y una correcta posición de las vísceras infradiafragmáticas. Estudios de seguimiento no han demostrado recurrencia de la eventración ni complicaciones pulmonares o de la pared torácica a largo plazo $^{6}$. En los casos de pacientes asintomáticos y con compromiso parcial del diafragma, no está clara la indicación de cirugía. Algunos autores recomiendan realizar cirugía correctora en todos los casos, por tratarse de una intervención con mínimo riesgo y resultados favorables a largo plazo?.

\section{Bibliografía}

1.- THOMAS T V. Congenital eventration of diaphragm. Ann Torac Surg 1970; 10: 180-92.

2.- MOORE K L, PERSAUD T V N. Editores. Before we are born. $5^{\text {th }}$ Edition 1998. W.B. Saunders Co. Philadelphia USA. pp 181-95.

3.- DESLAURIERS J. Eventration of the diaphragm. Chest Surg Clin of Nort Am 1998; 8: 315-31.

4.- KULKARNI M L, SNEHAROOPA B, VANI H N, NAWAZ S, KANNAN B, KULKARNI P M. Eventration of the Diaphragm and Associations. Indian J Pediatr 2007; 74: 202-5.

5.- ZÚÑIGA S, SOTO S, GARCÍA C, CAUSSADE S, SÁNCHEZ I, MONTES P, et al. Experiencia Clínica en Eventración Diafragmática Infantil. Rev Chil Cir 2000; 52: 365-70.

6.- BISHOP H C, KOOP C E. Acquired Eventration of the Diaphragm in Infancy. Pediatrics 1958; 22: 108896.

7.- ANSHU S, POONAM S, SINGH R J, VEENA S. Eventration of Diaphragm: Embryological basis. J Anat Soc India 2005; 54: 1-9.

8.- TSUGAWA C, KIMURA K, NISHIJIMA E, MURAJI T, YAMAGUCHI M. Diaphragmatic eventration in infants and children: is conservative treatment justified?. J Pediatr Surg 1997; 32: 1643-4.

9.- KIZILCAN F, TANYEL F C, HICSONMEZ A, BUYUKPAMUKCU N. The long term results of diaphragmatic plication. J Pediatr 1993; 28: 42-4.

10.- REILINGH V, KOENS B, VOS A. Surgical treatment of diaphragmatic eventration caused by phrenic nerve injury in the newborn. J Pediatr Surg 1998; 33: 602-5.

11.- LANGER J C, FILLER R M, COLES J, EDMONDS J F. Plication of the diaphragm for infants and young children with phrenic nerve palsy. J Pediatr Surg 1988; 23: 749-51.

12.- BIELINSKA M, JAY P Y, ERLICH J M, MANNISTO $\mathrm{S}$, URBAN Z, HEIKINHEIMO M, et al. Molecular genetics of congenital diaphragmatic defects. Ann Med 2007; 39: 261-74.

Correspondencia a:

Dr. Cristián García B.

Depto. Radiología, Facultad de Medicina

Pontificia Universidad Católica

Marcoleta $367,2^{\circ}$ piso - Santiago

E-mail: cgarcia@med.puc.cl 